\title{
OVITRAP SURVEILLANCE OF THE DENGUE VECTORS Aedes aegypti AND Aedes albopictus IN SELECTED ENDEMIC AREAS IN SANDAKAN, SABAH
}

\author{
Mohd Amierul \\ Fikri $\mathbf{M}^{1+}$ \\ iD Faizul Akmal AR ${ }^{2}$ \\ Mohd Farihan MYs
}

\author{
${ }^{1,2,3}$ Institute For Public Health, National Institute of Health, Ministry of \\ Health Malaysia. \\ 'Email:amierulfikri@gmail.com Tel:+60333628711 \\ 'Email:faizul.abdrahim@moh.gov.my Tel: +60333628753 \\ 'Email:farihanmy@moh.gov.my Tel:+60333628765
}

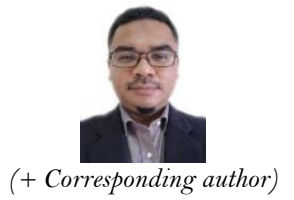

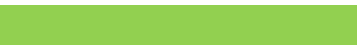

Article History

Received: 4 January 202 Revised: 27 January 2021

Accepted: 10 February 2021

Published: 22 February 2021

\section{Keywords}

Ovitrap

Aedes aegypti

Aedes albopictus

Dengue

Vector-borne

Malaysia.

\section{ABSTRACT}

Ovitrap technique could be considered an efficient tool for monitoring of Aedes populations. This study aimed to monitor the dengue vector population and to provide baseline data of vector density in selected endemic areas. 1600 ovitraps were placed indoor and outdoor randomly in selected houses from January till July 2014 at eight selected localities. $96 \%-100 \%$ of ovitraps were recovered after seven days. In total, 9399 larvae were examined of which 2674 (28.2\%) were Ae. Aegypti and 6752 (71.8\%) Ae. albopictus. Ae. albopictus were dominant than Ae. aegypti in every locality. Highest collection of Ae. albopictus was recorded in Kampung Air (total larvae = 1357), followed by Kampung Bokara (total larvae $=1165$ ) and Taman Fajar (total larvae $=846)$. Three main localities that recorded highest collection of Ae. aegypti were Kampung Bokara $($ total larvae $=504)$, Kampung Air $($ total larvae $=457)$ and Taman Fajar (total larvae $=$ 341). Ae. albopictus was found more abundant compared to Ae. aegypti. The ovitrap index recorded in all localities (ranged 18.0\% - 59.0\%) was more than the transmission threshold (10\%). Mix breeding of Ae. aegypti and Ae. albopictus were also detected for outdoor ovitraps. In conclusion, this study found that selected localities in Sandakan district have a high risk for transmission and outbreaks of dengue. Furthermore, this study also provided a baseline data of Aedes density for further planning of prevention and control activities.

Contribution/Originality: This study documents the ovitrap surveillance as an important tool for management and planning of dengue vector strategy focusing on endemic areas.

\section{INTRODUCTION}

Dengue is currently considered an important public health problem all over the world. Its occurrence has been notified and registered in more than 100 countries including most of tropical regions, China and Australia [1]. Malaysia had more than 38, 000 notified cases in each of the past six years [2]. In order to evolve an effective control mechanism, it is therefore very important to develop accurate methods that able to estimate adult population of Aedes. However, collection of sufficient numbers of Aedes sp indoors and outdoors is very difficult. In Malaysia, ovitrap and larval survey have been applied to monitor dengue vectors abundance in urban and suburban localities. Previous studies revealed that ovitrap was more effective than the larval survey for Aedes surveillance due to more numbers of Aedes were collected using ovitrap compared with larval survey [3-5]. Ovitrap surveys could be considered a sensitive and an efficient technique for detecting and monitoring Aedes populations at low densities and where the Breteau Index (BI) values are very low [6, 7]. Furthermore, the ovitraps are safe, 
economical and environment-friendly surveillance tools. Ovitrap is one of the cost-effective and important tools for Aedes surveillance in dengue control [8]. Previous studies found that surveillance using ovitraps could implemented for the prediction of outbreak, particularly in areas of low Aedes infestation, and has been suggested as a surveillance tool in dengue control $[6,7,9]$. Ovitrap surveillance is useful for management and planning of dengue vector strategy. This method is an important tool to provide spatial and temporal data in monitoring the impact of control measures [10]. Moreover, the application of ovitraps is advised for differentiating the infestation levels between the selected areas, focusing in high-risk areas [10]. Sandakan is one of the districts situated in Sabah, Malaysia and had recorded a significant number of dengue cases over the past three years (2011-2013). This study was conducted to monitor the dengue vector population and also to provide baseline data of vector density for further planning of control activities in selected endemic areas.

\section{METHODOLOGY}

\subsection{Study Areas}

Eight localities were selected for the implementation of ovitrap surveillance Figure 1. Those localities were selected based on the recorded cases and outbreaks of dengue fever from the year 2011 till 2013 in Sandakan district. The selected localities were Taman Fajar (TF), Taman Mawar (TM), Taman Airport (TA), Taman Kenari (TK), Taman Rajawali (TR), Taman Merpati Baru (TMB), Kampung Bokara (KB) and Kampung Air (KA) Table 1. A total of two hundred ovitraps were placed (indoor and outdoor) at randomly selected houses in each locality. Four ovitraps were allocated at each selected house (two were placed indoor, two were placed outdoor) [11].
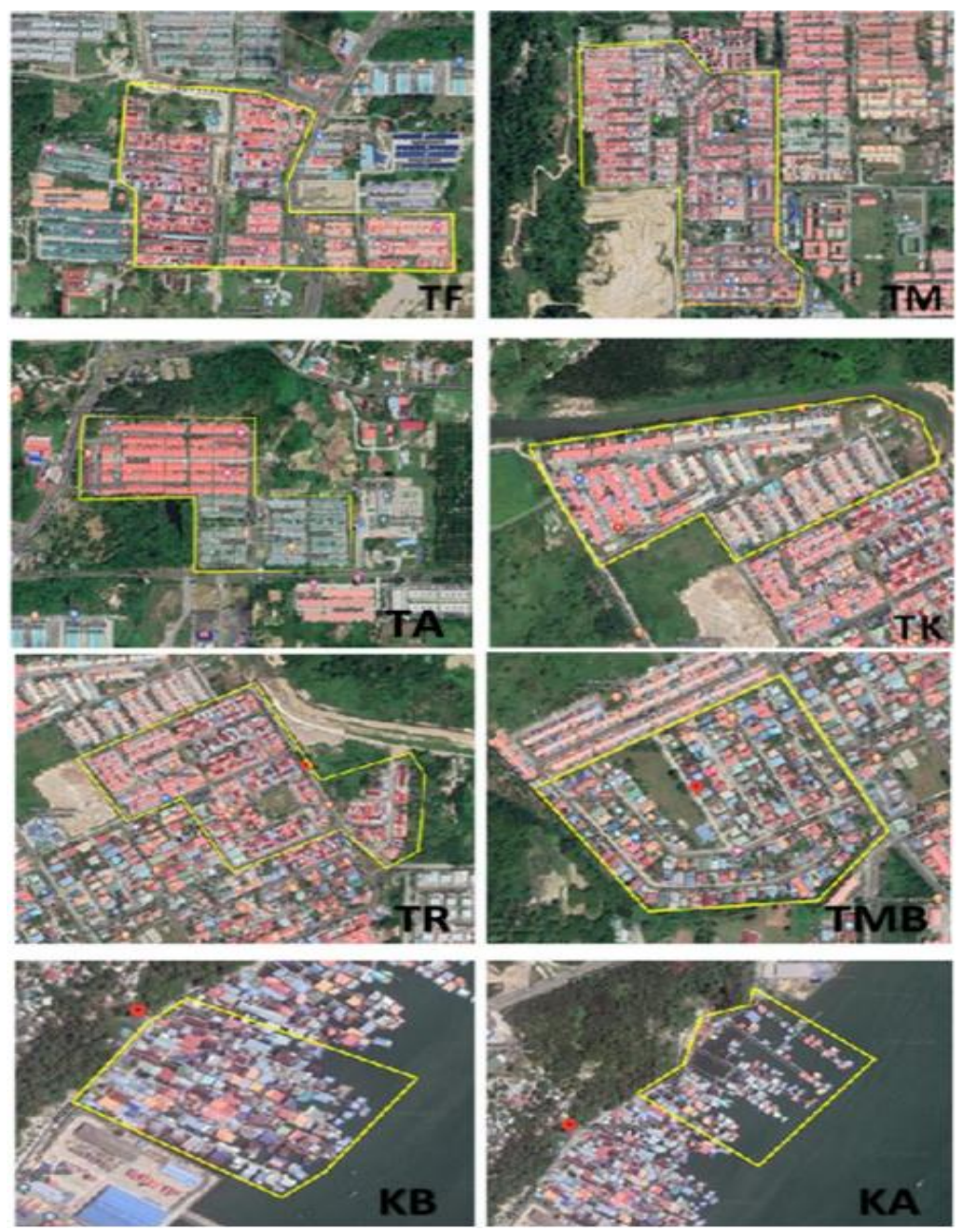

Figure-1. Map of study localities for ovitrap surveillance in Sandakan district, Sabah.

Note: *TF-Taman Fajar, TM-Taman Mawar, TA-Taman Airport, TK-Taman Kenari, TR-Taman Rajawali

TMB-Taman Merpati Baru, KB-Kampung Bokara, KA-Kampung Air 
Table-1. The study localities in Sandakan district, Sabah.

\begin{tabular}{|c|c|c|c|c|}
\hline Locality & $\begin{array}{c}\text { GPS } \\
\text { Coordinate }\end{array}$ & Category & $\begin{array}{c}\text { House / } \\
\text { Residential Type }\end{array}$ & $\begin{array}{l}\text { Ecological } \\
\text { condition }\end{array}$ \\
\hline$\overline{\mathrm{TF}}$ & $\begin{array}{l}\text { Long:5.888290, } \\
\text { Lat: } 118.055312\end{array}$ & Urban & Planned terraces & $\begin{array}{l}\text { - Surrounded with vegetation } \\
\text { - Well managed area, proper waste disposal } \\
\text { management }\end{array}$ \\
\hline TM & $\begin{array}{l}\text { Long:5.844443, } \\
\text { Lat: } 18.032327\end{array}$ & Urban & Planned terraces & $\begin{array}{l}\text { - Surrounded with vegetation and small farm } \\
\text { - Well managed area, proper waste disposal } \\
\text { management }\end{array}$ \\
\hline TA & $\begin{array}{l}\text { Long:5.892609, } \\
\text { Lat: } 118.061454\end{array}$ & Urban & Planned terraces & $\begin{array}{l}\text { - Surrounded with vegetation, small farm and } \\
\text { house landscape } \\
\text { - Well managed area, proper waste disposal } \\
\text { management }\end{array}$ \\
\hline TK & $\begin{array}{l}\text { Long:5.895308, } \\
\text { Lat: } 18.044252\end{array}$ & Urban & Planned terraces & $\begin{array}{l}\text { - Surrounded with small farm, few illegal } \\
\text { disposal area } \\
\text { - Well managed area }\end{array}$ \\
\hline TR & $\begin{array}{l}\text { Long:5.894269, } \\
\text { Lat: } 18.046760\end{array}$ & Urban & Planned terraces & $\begin{array}{l}\text { - Surrounded with vegetation, no man's land, } \\
\text { small scale construction site } \\
\text { - Well managed area, generally clean }\end{array}$ \\
\hline TMB & $\begin{array}{l}\text { Long:5.890547, } \\
\text { Lat:1 18.042646 }\end{array}$ & Urban & Planned terraces & $\begin{array}{l}\text { - Surrounded with vegetation } \\
\text { - Well managed area, proper waste disposal } \\
\text { management }\end{array}$ \\
\hline KB & $\begin{array}{l}\text { Long: } 5.813008, \\
\text { Lat: } 118.079749\end{array}$ & $\begin{array}{l}\text { Suburban, } \\
\text { coastal }\end{array}$ & $\begin{array}{l}\text { Semi-planned, } \\
\text { water-village }\end{array}$ & $\begin{array}{l}\text { - Coastal area, near vegetation area } \\
\text { - Improper water supply system } \\
\text { - Poor waste disposal management }\end{array}$ \\
\hline KA & $\begin{array}{c}\text { Long: } 5.814307, \\
\text { Lat: } 118.08136\end{array}$ & $\begin{array}{l}\text { Suburban, } \\
\text { coastal }\end{array}$ & $\begin{array}{l}\text { Semi-planned, } \\
\text { water-village }\end{array}$ & $\begin{array}{l}\text { - Coastal area, near vegetation area } \\
\text { - Improper water supply system } \\
\text { - Poor waste disposal management }\end{array}$ \\
\hline
\end{tabular}

Note: *TF-Taman Fajar, TM-Taman Mawar, TA-Taman Airport, TK-Taman Kenari, TR-Taman Rajawali TMB-Taman Merpati Baru, KB-Kampung Bokara, KAKampung Air.

\subsection{Ovitrap Setting}

The sampling of ovitrap as described by Lee [6] was applied in this surveillance based on the Malaysian Ministry of Health Guidelines [12]. Each ovitrap comprised of a $300 \mathrm{ml}$ black plastic container (6.5 cm in diameter and $9.0 \mathrm{~cm}$ in height). Clean tap water was added until it reached the level of $5.5 \mathrm{~cm}$ and a hardboard paddle for oviposition $(10 \mathrm{~cm} \times 2.5 \mathrm{~cm} \times 0.3 \mathrm{~cm})$ was placed with the rough surface facing upwards in every ovitraps. A total of 200 ovitraps were placed indoor (100 ovitraps) and outdoor (100 ovitraps) in randomly selected houses after obtaining consent from the house owner. Collection of ovitraps were done after seven days and transported to the Sandakan Health District Office laboratory. The contents of ovitrap including paddles were poured individually into covered and labelled plastic containers $(15 \mathrm{~cm} \mathrm{x} 7 \mathrm{~cm} \mathrm{x} 8.5 \mathrm{~cm})$.

In our study, indoor placement refers to the interior of the houses while outdoor placement refers to the outside of the houses but confined to house compound area only. As this study aimed to provide baseline data of Aedes abundance in all selected areas, therefore only one ovitrap surveillance was performed in each area. The surveillance of ovitrap was conducted in January till July 2014.

\subsection{Identification of Larvae}

The ovitraps were retrieved after 7 days and send to Sandakan Health District Office Vector laboratory. The identification was done by trained Public Health Assistants and the results were verified by entomologist. The contents of the retrieved ovitraps were poured into plastic container and labelled. Tap water (exposed for 24-48 hours before used) was added into the container. The larvae were counted and $3^{\text {rd }}$ and $4^{\text {th }}$ instar-larvae were identified based on the species key by Mahadevan, et al. [13]. The larvae were counted and identified under a 
compound microscope (Nikon Eclipse E200, Japan) based on taxonomy keys. For each positive ovitrap, the larval numbers were recorded.

\subsection{Data Analysis}

The abundance of Aedes sp. larvae in selected endemic areas were analyzed as follows:

i. Ovitrap index (Ovitrap Index), the percentage of positive ovitrap against the total number of ovitraps recovered for each site.

Ovitrap Index $(\mathrm{OI})=\quad$ Number of positive ovitrap $\quad \mathrm{X} \quad 100$

Number of ovitrap collected

ii. The number of Aedes sp. larvae per recovered ovitrap.

iii. Mean number of larvae (per species) per total number of recovered ovitrap for both or either indoor or outdoor:

Mean number of larvae/ovitrap $=\quad$ Total number of larvae $\quad X \quad 100$

Total number of ovitrap collected

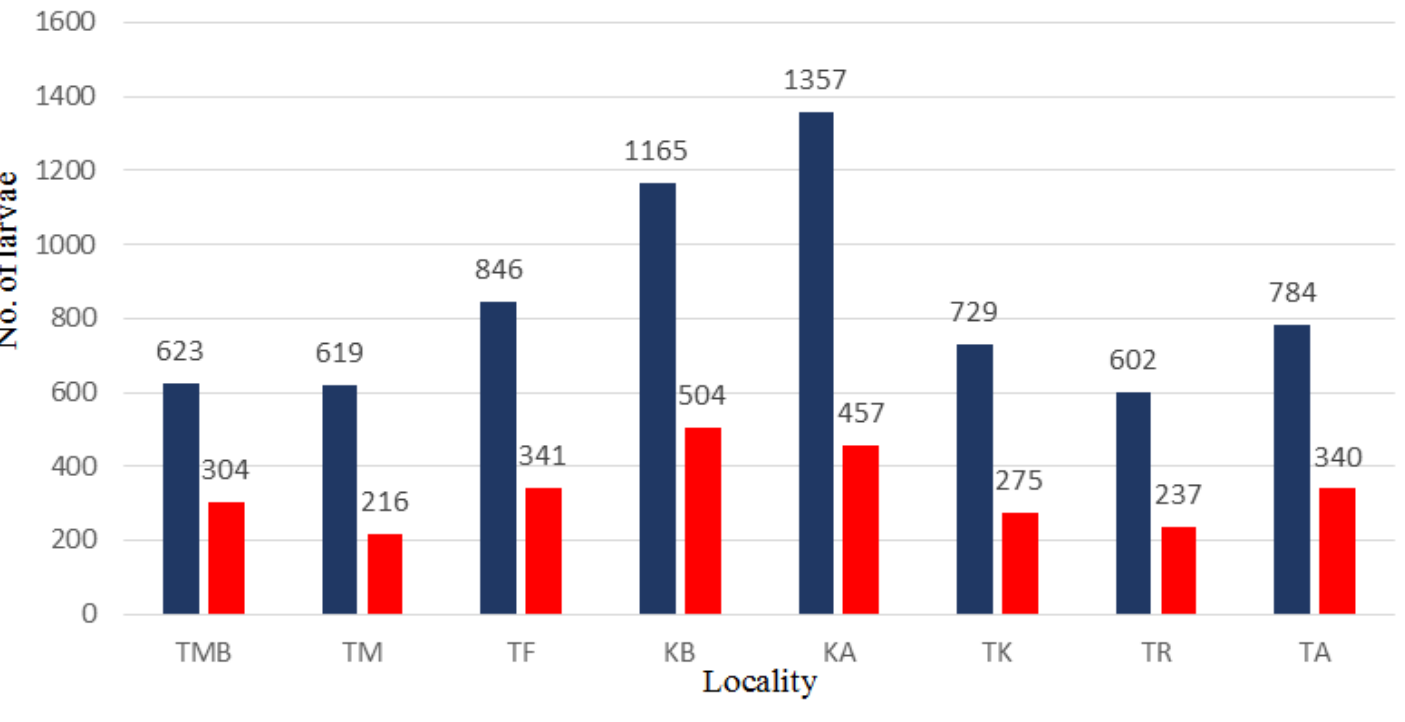

Figure-2. Total number of Aedes larvae collected using ovitraps in Sandakan, Sabah.

Table-2. Ovitrap index (OI) and mean number of Ae. aegypti and Ae. albopictus collected indoor and outdoor using ovitraps

\begin{tabular}{|c|c|c|c|c|}
\hline \multirow[t]{2}{*}{ Study area } & \multirow[t]{2}{*}{ Ovitrap placement } & \multirow[t]{2}{*}{ Ovitrap Index (\%) } & \multicolumn{2}{|c|}{ Mean larvae per recovered ovitrap } \\
\hline & & & Ae.aegypti & Ae.albopictus \\
\hline \multirow[t]{2}{*}{ TMB } & Indoor & 20.0 & $6.25 \pm 1.643$ & - \\
\hline & Outdoor & 30.6 & - & $9.86 \pm 1.904$ \\
\hline \multirow[t]{2}{*}{$\mathrm{TM}$} & Indoor & 18.0 & $7.72 \pm 2.109$ & - \\
\hline & Outdoor & 32.0 & $11.50 \pm 3.536$ & $11.52 \pm 3.572$ \\
\hline \multirow[t]{2}{*}{$\mathrm{TF}$} & Indoor & 28.0 & $9.71 \pm 1.823$ & - \\
\hline & Outdoor & 40.0 & $5.50 \pm 0.707$ & $9.97 \pm 3.279$ \\
\hline \multirow[t]{2}{*}{ KB } & Indoor & 39.7 & $9.74 \pm 3.015$ & - \\
\hline & Outdoor & 52.0 & $7.00 \pm 2.828$ & $11.53 \pm 3.421$ \\
\hline \multirow[t]{2}{*}{$\mathrm{KA}$} & Indoor & 48.0 & $12.00 \pm 3.804$ & - \\
\hline & Outdoor & 59.2 & $6.75 \pm 1.708$ & $9.87 \pm 1.884$ \\
\hline \multirow[t]{2}{*}{ TK } & Indoor & 24.0 & $9.50 \pm 1.769$ & - \\
\hline & Outdoor & 32.0 & 6.00 & $9.13 \pm 2.172$ \\
\hline \multirow[t]{2}{*}{ TR } & Indoor & 20.4 & $7.90 \pm 1.971$ & - \\
\hline & Outdoor & 30.0 & $5.33 \pm 1.528$ & $9.70 \pm 1.462$ \\
\hline \multirow[t]{2}{*}{$\mathrm{TA}$} & Indoor & 33.3 & $8.25 \pm 2.272$ & - \\
\hline & Outdoor & 35.1 & $5.50 \pm 0.707$ & $9.25 \pm 2.170$ \\
\hline
\end{tabular}




\section{RESULTS}

A total of 1600 ovitraps were placed indoor and outdoor randomly in selected houses from January till July 2014. During the surveys, upon the placement of ovitraps, $96 \%-100 \%$ were recovered after seven days. In total, 9399 larvae were examined of which 2674 (28.2\%) were Ae. Aegypti and 6752 (71.8\%) Ae. albopictus Figure 2. Ae. albopictus were collected higher than Ae. aegypti in every study locality. Highest collection of Ae. albopictus was recorded in Kampung Air (total larvae $=1357$ ), followed by Kampung Bokara (total larvae $=1165$ ) and Taman Fajar (total larvae $=846)$. Three main localities that recorded highest collection of Ae. aegypti were Kampung Bokara (total larvae $=504)$, Kampung Air (total larvae $=457$ ) and Taman Fajar (total larvae $=341)$. Overall, based on the total number of Aedes species collected during this study, Ae. albopictus was found more abundant compared to Ae. aegypti.

Table 2 summarized the ovitrap index (OI) and the mean number of Ae aegypti and Ae albopictus collected indoor and outdoor according to the study localities. The result showed that indoor and outdoor ovitraps were found positive with Aedes species at all study localities. The OI recorded in all localities was more than the transmission threshold (10\%). This result indicated that the localities were considered at high risk of dengue transmission [9]. In this study, OI for indoor and outdoor were found to be in the range of $18 \%-48 \%$ and $30 \%-59 \%$ respectively. Highest OI for both indoor and outdoor were observed at Kampung Air with recorded mean larvae per recovered ovitrap of $12.00 \pm 3.804$ and $9.87 \pm 1.884$ followed by Kampung Bokara with recorded mean larvae per recovered ovitrap 9.74 \pm 3.015 and $11.53 \pm 3.421$. Mix breeding of Ae. aegypti and Ae. albopictus were identified for outdoor ovitraps at few localities such as Taman Mawar, Taman Fajar, Kampung Bokara, Kampung Air, Taman Kenari, Taman Rajawali and Taman Airport. However, no mix breeding of Ae. aegypti and Ae. albopictus were detected for indoor ovitraps.

\section{DISCUSSION}

This study utilized ovitrapping technique as Aedes surveillance tool and showed that it remains as economical and reliable tool to detect the abundance of Ae. aegypti and Ae. albopictus. Similar findings were reported by Braga, et al. [4]; Rozilawati, et al. [5]; Lee [6]; De Melo, et al. [14]; Noor Afizah, et al. [15] where the authors found that ovitrapping was a useful, more sensitive and effective to monitor Aedes infestation than standard larval survey activities.

Based on the result in Figure 2, it was found that Ae. albopictus population is highly abundant and dominated the selected localities in Sandakan district, Sabah especially as an outdoor breeder. This finding is supported by previous studies $[5,15,16]$ which reported Ae. albopictus was more abundant and dominant outdoor than indoor. The total number of Aedes larvae collected from this study indicated that Ae albopictus and Ae aegypti as an outdoor and indoor breeder respectively. Although few studies in Malaysia $[6,17]$ reported that these two species can be found for both indoors and outdoors, Ae aegypti was predominantly identified to be dominant indoors and Ae. albopictus to be dominant outdoors as shown by this study. Kampung Air and Kampung Bokara which were located in coastal area of Sandakan district had recorded the highest number of indoor and outdoor Aedes larvae compared to other localities. This may due to the occurrence of outdoor breeding containers mainly plastic containers caused by improper waste disposal and management at these localities. The absence proper water supply system and refuse disposal has given rise of a large number of water storage containers both indoors and outdoors [18]. This led to high abundance of Aedes sp in the area that contributed to high oviposition in the ovitraps. Study by Mahmud, et al. [19] mentioned that one of the main Aedes aegypti indoor breeding container was water drum used as water storage container. As reported by Chang and Jute [18] the abundance of Ae. albopictus was higher in coastal and rural areas due to lack of basic infrastructures and constant water storage activities.

The results Table 1 revealed that more positive ovitraps were found outdoors rather than indoors in all localities which were correspond with previous study by Dibo, et al. [20]. In this study, the ovitrap index (OI) had indicated that all the localities were stratified as at high risk of dengue transmission (OI>10\%) [9]. Therefore, 
preventive and integrated control measures should be planned by vector control program in Sandakan district to eradicate Aedes breeding places as well as to enhance awareness on Aedes prevention among residents. To monitor the density of Aedes population and the risk of dengue transmission in these localities, we suggest that the surveillance of the mosquitoes to be continuously performed using standard ovitraps techniques [7, 21]. The variation of OI recorded in each locality may due to time variation, temperature and rainfall factors in Sandakan from January to July 2014. Data obtained from local authorities showed that there were increasing trend of temperature and rainfall data recorded in Sandakan starting from May to July 2014. Further investigation could be done to explore the relationship between meteorological factors with OI in these areas.

The results in Table 2 also demonstrated the existence of mix breading for outdoor ovitraps at most of the study localities. Mix breeding of Ae. aegypti and Ae. albopictus were found in outdoor ovitraps at most of the localities and consistent with other studies in Indonesia and Malaysia [5, 22, 23]. Epidemiologically, mixed breeding is significant, as it is a demonstration of interspecific competitive displacement.

\section{CONCLUSION}

Our study manifested that the Aedes population can be observed and monitored effectively by applying ovitraps in selected localities continuously. Furthermore, this study provided a baseline data of Aedes density thus, assist for further planning of control activities in selected endemic areas. In conclusion, this study found that these selected localities in Sandakan district have a high risk for transmission and outbreaks of dengue. Findings from this study offered important entomological data for the development of effective integrated vector control program to combat Aedes in this area.

Funding: Authors would like to extend their gratitude to the staff of vector-borne unit, Sandakan Health District Office, Sabah for their assistance and support in this study.

Competing Interests: The authors declare that they have no competing interests.

Acknowledgement: Authors would like to thank the Director General of Health, Malaysia for his permission to publish this paper.

\section{REFERENCES}

[1] A. Kroeger and M. B. Nathan, "Dengue: Setting the global research agenda," The Lancet, vol. 368, pp. 2193-2195, 2006.Available at: https://doi.org/10.1016/s0140-6736(06)69873-5.

[2] A. H. Mohd-Zaki, J. Brett, E. Ismail, and M. L'Azou, "Epidemiology of dengue disease in Malaysia (20oo-2012): A systematic literature review," PLoS Negl Trop Dis, vol. 8, p. e3159, 2014.

[3] C. C. d. A. Marques, G. R. d. A. M. Marques, M. d. Brito, L. G. d. Santos Neto, V. d. C. Ishibashi, and F. d. A. Gomes, "Comparative study of the efficiency of larval and ovitraps for the surveillance of dengue and yellow fever vectors," Public Health Magazine, vol. 27, pp. 237-241, 1993.

[4] I. A. Braga, A. d. C. Gomes, M. Nelson, R. d. C. G. Mello, D. P. Bergamaschi, and J. M. P. d. Souza, "Comparison between larval research and oviposition trap for the detection of Aedes aegypti," Journal of the Brazilian Society of Tropical Medicine, vol. 33, pp. 347-353, 2000.Available at: https://doi.org/10.1590/s0037-86822000000400003

[5] H. Rozilawati, K. Tanaselvi, W. Nazni, S. Mohd Masri, J. Zairi, C. Adanan, and H. Lee, "Surveillance of aedes albopictus skuse breeding preference in selected dengue outbreak localities, peninsular Malaysia," Tropical Biomedicine, vol. 32 , pp. 49-64, 2015.

[6] H. L. Lee, "Aedes ovitrap and larval survey in several suburban communities in Selangor Malaysia," Mosquito-Borne Diseases Bulletin, vol. 9, pp. 9-15, 1992.

[7] D. A. Focks, "A review of entomological sampling methods and indicators for dengue vectors," Dengue Bull, vol. 28, pp. $10-34,2000$.

[8] M. Service, "Importance of ecology in Aedes aegypti control," The Southeast Asian journal of Tropical Medicine and Public Health, vol. 23, pp. 681-690, 1992 . 
[9] A. Tham, Surveillance of mosquitoes. In: F.S.P. Ng छ H.S. Yong, eds. Mosquito and Mosquito Borne Disease. Kuala Lumpur: Malaysian Academy of Sciences, 2000.

[10] L. L. N. Serpa, G. R. A. M. Marques, A. P. de Lima, J. C. Voltolini, M. de Brito Arduino, G. L. Barbosa, V. R. Andrade, and V. L. C. de Lima, "Study of the distribution and abundance of the eggs of Aedes aegypti and Aedes albopictus according to the habitat and meteorological variables, municipality of São Sebastião, São Paulo State, Brazil," Parasites E Vectors, vol. 6, pp. 1-11, 2013.

[11] N. Wijegunawardana, Y. Gunawardene, T. Chandrasena, R. Dassanayake, N. Udayanga, and W. Abeyewickreme, "Evaluation of the effects of Aedes vector indices and climatic factors on dengue incidence in Gampaha District, Sri Lanka," BioMed Research International, vol. 2019, pp. 1-11, 2019.

[12] MOH, "Guidelines on the use of ovitraps for aedes surveillance," ed Malaysia: Ministry of Health Malaysia, 1997, pp. 1-20.

[13] S. Mahadevan, W. Cheong, and A. Hassan, Vectors of dengue and dengue haemorrhagic fever in West Malaysia. Kuala Lumpur: Institute for Medical Research, 1973.

[14] D. P. O. De Melo, L. R. Scherrer, and Á. E. Eiras, "Dengue fever occurrence and vector detection by larval survey, ovitrap and MosquiTRAP: A space-time clusters analysis," PloS One, vol. 7, p. e42 125, 2012.

[15] A. Noor Afizah, W. Mohd Arif, H. L. Lee, and A. Nazni, "Ovitrap surveillance of Aedes aegypti and Aedes albopictus in dengue endemic areas in Keramat and Shah Alam, Selangor in 2016," IIUM Medical Journal Malaysia, vol. 17, pp. 59$64,2018$.

[16] S. Snr, Y. Norma-Rashid, and M. Sofian-Azirun, "Mosquitoes larval breeding habitat in urban and suburban areas, Peninsular Malaysia," World Acad Sci Eng Technol, vol. 58, pp. 569-573, 2011.

[17] H. L. Lee, "A nationwide resurvey of the factors affecting the breeding of Aedes aegypti (L.) and Aedes albopictus (Skuse)(Diptera: Culicidae) in urban towns of peninsular Malaysia-1988-1989," Trop Biomed, vol. 8, pp. 57-60, 1991.

[18] M. Chang and N. Jute, "Distribution and density of aedes aegypti and aedes ALBOPICTUS (SKUSE) in SARAWAK," Med. J. Malaysia, vol. 37, pp. 205-210, 1982.

[19] M. Mahmud, H. Mutalip, N. Lodz, and H. Shahar, "Study on key Aedes spp breeding containers in dengue outbreak localities in Cheras district, Kuala Lumpur," International Journal of Mosquito Research, vol. 5, pp. 23-30, 2018.

[20] M. R. Dibo, F. Chiaravalloti-Neto, M. Battigaglia, A. Mondini, E. A. Favaro, A. A. Barbosa, and C. M. Glasser, "Identification of the best ovitrap installation sites for gravid Aedes (Stegomyia) aegypti in residences in Mirassol, state of São Paulo, Brazil," Memórias do Instituto Oswaldo Cruz, vol. 100, pp. 339-343, 2005.

[21] C. J. Beech, J. Nagaraju, S. Vasan, R. I. Rose, R. Y. Othman, V. Pillai, and T. Saraswathy, "Risk analysis of a hypothetical open field release of a self-limiting transgenic Aedes aegypti mosquito strain to combat dengue," Asia Pacific Journal of Molecular Biology and Biotechnology, vol. 17, pp. 97-108, 2009.

[22] N. Syarifah, T. Rusmatini, T. Djatie, and F. Huda, "Ovitrap ratio of Aedes aegypti larvae collected inside and outside houses in a community survey to prevent dengue outbreak, Bandung, Indonesia, 2007," Proc Assoc Southeast Asian Nations Congr Trop Med Parasitolol, vol. 3, pp. 116-120, 2008.

[23] R. Norzahira, O. Hidayatulfathi, H. Wong, A. Cheryl, R. Firdaus, H. Chew, K. Lim, K. Sing, M. Mahathavan, and W. Nazni, "Ovitrap surveillance of the dengue vectors, Aedes (Stegomyia) aegypti (L.) and Aedes (Stegomyia) albopictus Skuse in selected areas in Bentong, Pahang, Malaysia," Tropical biomedicine, vol. 28, pp. 48-54, 2011.

Views and opinions expressed in this article are the views and opinions of the author(s), International Research Journal of Insect Sciences shall not be responsible or answerable for any loss, damage or liability etc. caused in relation to/arising out of the use of the content. 